\title{
BREVES CONSIDERAÇÕES SOBRE O SOFRIMENTO SOCIAL ${ }^{1}$
}

\section{JULIO TOMÉ ${ }^{2}$}

RESUMO: Pretende-se neste trabalho defender a ideia de que o sofrimento pode ser social. Com a ideia de sofrimento social, pretende-se oferecer uma explicação social frente às visões providencialista e neoliberal (individualista) do sofrimento. Argumenta-se que o sofrimento não é fruto do desejo de Deus, assim como não é apenas uma experiência individual que reflete as escolhas de cada pessoa. O sofrimento, portanto, pode ter suas causas, origens e manutenção devidos à organização social, cultural e histórica em que as pessoas estão inseridas, i.e., pode ser socialmente constituído.

PALAVRAS-CHAVE: Sofrimento Social. Providencialismo Divino. Neoliberalismo. Individualismo.

ABSTRACT: The objective of this paper is to defend the idea that suffering can be social. With the idea of social suffering, it is intended to offer a social explanation in front of the providentialism and neoliberal (individualistic) views of suffering. It is argued that suffering is not the fruit of God's desire, neither is it merely an individual experience that reflects the choices of each person. Suffering, therefore, can have its causes, origins and maintenance due to the social, cultural and historical organization in which people are inserted, in other words, it can be socially constituted.

KEYWORDS: Social suffering. Divine providentialism. Neoliberalism. Individualism.

Neste trabalho pretende-se, a partir de uma discussão filosófica, defender a ideia de que o sofrimento pode ser social. Deste modo, não se trata do sofrimento enquanto um problema psicológico. Contudo, tão pouco tem a ver com a perspectiva schopenhaueriana que o mundo é sofrimento e que, independentemente das ações humanas, as pessoas sempre sofrerão, em um círculo ad infinitum de desejos e sofrimentos. Assim, o sofrimento em questão neste trabalho diz respeito ao sofrimento socialmente evitável, i.e., discutir-se-á o sofrimento enquanto um problema social e seus aspectos culturais e históricos.

Para que este propósito seja cumprido, deseja-se iniciar o trabalho com o seguinte exemplo, retirado do filme brasileiro dirigido por Anna Muylaert, Que Horas Ela Volta? Dona

\footnotetext{
${ }^{1}$ O presente trabalho foi realizado com apoio da Coordenação de Aperfeiçoamento de Pessoal de Nível Superior - Brasil (CAPES) - código de financiamento 001. Uma versão anterior desse texto foi apresentada no GT de Teorias da Justiça da ANPOF no 11th Principia, organizado pelo PPGFIL/UFSC, em 2019. Agradeço a organização e os presentes por suas considerações, críticas e comentários enriquecedores sobre o texto. Agradeço também a Samantta Lopes Portela pela leitura crítica e correções sugeridas, assim como ao corpo editorial da revista IDEAÇÃO.

${ }^{2}$ Doutorando em filosofia pela Universidade Federal de Santa Catarina (UFSC). E-mail: juliohc7@hotmail.com.
} 
Val (interpretada por Regina Casé) é uma empregada doméstica pernambucana que saiu de seu Estado natal há mais ou menos 13 anos, para tentar conseguir uma "vida melhor", para si e sua família, na cidade de São Paulo, mas deixando para trás sua filha, Jéssica, ainda criança. Em São Paulo, Val foi babá de Fabinho e, posteriormente, se tornou empregada doméstica dos pais de Fabinho, Bárbara e José Carlos, que formam uma família de classe média alta em São Paulo. No filme a vida de Val sofre uma abrupta mudança quando Jéssica resolve ir a São Paulo prestar o vestibular para o curso de arquitetura na FAU-USP.

A partir do enredo principal do filme estrelado por Regina Casé pretende-se mostrar que há - por trás das questões óbvias apresentadas na obra cinematográfica, como a denúncia à desigualdade social, e as mudanças sociais que ocorreram no Brasil nos anos dos governos mais à esquerda com o Partido dos Trabalhadores (PT) - sofrimento. E que este sofrimento não é específico de Val (ou de tantas empregadas domésticas brasileiras, que deixam suas casas diariamente para cuidar da casa de outras pessoas, muitas vezes convivendo muito mais com a família de seus patrões do que com suas próprias famílias), mas fruto de condições históricas, culturais e sociais, às quais a personagem de Regina Casé está inserida. Deste modo, as angústias e dores da empregada doméstica do filme são vistas como representações do conceito de sofrimento social.

Deste modo, este trabalho tem como objetivo responder as seguintes questões: o que é sofrimento? O que é sofrimento social? Por que o exemplo retirado do filme Que Horas ela Volta? retrata o caso de sofrimento social e não meramente um sofrimento individual (de Val e, posteriormente, de Jéssica)? Na defesa de que há sofrimento social - que pode ser percebido na história do filme - começa-se por definir o conceito de sofrimento e, posteriormente, discutese e rejeita-se as ideias que afirmam que o sofrimento é fruto do desejo de Deus (visão providencialista do sofrimento) ou meramente consequência de ações individuais e, portanto, não pode ser visto em um todo (visão "neoliberal"/individualista do sofrimento). Por fim, define-se o conceito de sofrimento social como uma maneira de compreender alguns dos problemas estruturais ligados ao mundo moderno, exemplificando-os com o caso de Val e Jéssica.

\section{O que é Sofrimento?}

Para se responder à questão “o que é sofrimento?” por meio de um viés filosófico, iniciase a partir da ideia apresentada por Wilkinson (2005) de que sofrimento é, em essência, uma 
experiência individual. Parte-se dessa ideia, pois quer-se, como será visto mais à frente, defender a ideia de que não é porque a experiência do sofrimento seja sempre uma experiência individual, indizível (unsharability) que isso implique no fato do sofrimento ser individual, i.e., que as causas e as soluções do sofrimento dizem respeito apenas às pessoas que estão vivenciando a dor. Wilkinson (2005) reconhece que a ideia de que cada pessoa experimenta o sofrimento do seu modo acaba por dificultar o trabalho de se definir o que é sofrimento. Mesmo assim, o autor define sofrimento, em um primeiro momento, como a capacidade de sentir dor. Claro, com essa ideia de sofrimento, é uma consequência lógica que uma pessoa não pode sentir a dor de outra pessoa, i.e., que se trata de uma experiência individual que não pode ser abertamente compartilhada com outra pessoa.

Para Wilkinson (2005), o sofrimento também possui um caráter de indizibilidade, que pode fazer com que a sua representação não seja clara e que desafie a capacidade das outras pessoas (espectadores, teóricos etc.) de fornecer uma expressão formal externa de conteúdo da experiência; i.e., uma vez que o sofrimento é sempre sentido/experienciado/experimentado de maneira individual e há o traço da indizibilidade, tem-se que o sofrimento torna-se e é visto sempre como um conceito "obscuro". Para Wilkinson (2005) o problema de se definir o sofrimento ${ }^{3}$ pode estar ligado ao fato de que ele parece ocorrer em uma ampla variedade de formas e fenômenos, sobre os quais, mesmo sendo sempre pessoal, se aceita a ideia de que pode ocorrer de diversos modos, em diversas maneiras, em diferentes fenômenos, podendo ser físico, psicológico, social, econômico, político e cultural. Assim sendo, o sofrimento é muito mais do que dor física e, portanto, experiências de luto e perda, isolamento social e afastamento pessoal podem ser caracterizados como sofrimento. $\mathrm{O}$ sofrimento também pode incluir sentimentos como a depressão, ansiedade, culpa, humilhação e angústia, e pode haver sofrimento em situações de privação material, em situações em que há perpetuação de injustiças sociais e a negação de liberdades civis.

\footnotetext{
${ }^{3}$ Para Wilkinson (2005), é por meio da imprecisão conceitual que alguns comentadores aceitam que o sofrimento tem o poder de violar e destruir a vida daquelas pessoas que o estão vivendo. E, desta maneira, a tentativa de se criar formas simbólicas para conferir um "significado" adequado ao sofrimento é geralmente abordada não apenas como um esforço intelectual, mas também como parte de um trabalho urgente de reconstrução social e cura psíquica. O autor afirma, contudo, que há uma controvérsia ética na questão da discussão do sofrimento: alguns autores afirmam que as pessoas que sofrem, que sentem muitas dores, não conseguem transmitir seus sentimentos - seus sofrimentos, suas dores, uma vez que há um caráter indizível (unsharability) do sofrimento; e deste modo, a consequência seria, portanto, a de respeitar o silêncio do sofrimento. Porém, segundo a interpretação de Wilkinson (2005), neste caso parece haver um paradoxo, pois, por meio do ponto de vista ético, pode-se também defender a necessidade de se falar e analisar o sofrimento, pois é somente assim que se conseguirá explicar quando é realmente necessário o silêncio, i.e., segundo o autor, com a ideia de silenciamento - em respeito às pessoas que estão sofrendo - pode-se acabar por apenas se perpetuar as situações que fazem as pessoas sofrerem, encobrindo e mistificando essas condições, e assim, pode-se defender a necessidade de se discutir o sofrimento e os infortúnios das pessoas; deve-se colocar o "dedo na ferida", como se fala popularmente.
} 
Wilkinson (2005) reconhece que a ideia de sofrimento apresentada implica na separação conceitual entre dor e sofrimento e que tal diferenciação serve apenas para obscurecer ainda mais a discussão, pois quando se evidencia que uma proporção significativa da experiência corporal da dor é constituída no nível da cultura e da sociedade, percebe-se que há uma estreita associação entre dor e sofrimento, mas também se assume a visão de que a dor é mais objetiva do que o sofrimento. Assim, deve-se ver "[...] dor como forma de sensação fisiológica e sofrimento como resposta fisiológica subjetiva à dor [...]" (WILKINSON, 2005, p. 21). Desta maneira, tem-se que enquanto a dor é concebida para ter um lugar corporal especifico, o sofrimento é muito mais extensivo que isso, seu domínio é mantido para além dos limites da mera sensação corporal, de modo a abranger toda a experiência da pessoalidade (personhood) - corpo, mente e espírito ${ }^{4}$.

Esta leitura estaria imbricada com a ideia da distinção entre mente e corpo, advinda do pensamento cartesiano. Contudo, segundo Wilkinson (2005), mesmo em uma situação sobre a qual aparentemente se lida com a ideia de dor enquanto um caráter objetivo, pode haver um traço subjetivo (cultural ou social) nela. Segundo o autor, há uma relação íntima entre experiências somáticas e frustrações sociais e políticas que parece ter um efeito estruturante sobre os significados pessoais que os indivíduos adquirem e criam para suas vidas. Assim, dado o fenômeno do sofrimento, se deve ter como objetivo "[...] alcançar formas mais efetivas de cuidados com a dor (Pain Care), a proteção dos Direitos Humanos, a justiça para os oprimidos e o fim da crueldade e das dificuldades" (WILKINSON, 2005, p. 43). O autor propõe que a dificuldade de dar sentido ao sofrimento humano não seja entendida como uma indicação de exigência de racionalização, mas sim como o envolvimento do sofrimento com a experiência. Sendo que esta falha de entendimento é, paradoxalmente, uma oportunidade para o entendimento.

A partir dessa essa ideia de sofrimento, que ainda é incipiente e pouco clara, é possível afirmar que a personagem Val do filme Que Horas Ela Volta?, interpretada pela atriz Regina Casé, apresentava aspectos de sofrimento. Por exemplo, o primeiro desses aspectos parece ser o de privação material: Val precisou sair de sua terra natal, e não teve dinheiro suficiente para levar Jessica consigo quando foi para São Paulo. Sem contar, claro, o sofrimento psicológico

\footnotetext{
${ }^{4}$ Assim, com esta ideia, pode haver dor sem sofrimento, por exemplo, como no caso que uma pessoa tatua seu corpo, pois neste caso se tem uma experiência fisiológica intensa de dor (das agulhas na pele) sem o sofrimento, sem o ato de sofrer dor. Haveria, deste modo, certa conotação positiva do sofrimento, é verdade.
} 
que foi para a personagem deixar sua filha e ir sozinha para São Paulo ${ }^{5}$. Já quando a empregada de Bárbara e José Carlos descobre que sua filha, Jéssica, irá viajar de Pernambuco para São Paulo, para fazer o vestibular e morar com ela, há um claro aspecto de angústia e medo - dois tipos de sofrimento, ao se aceitar a ideia de Wilkinson (2005) - presente na construção da narrativa ao redor da personagem. Esses sofrimentos experienciados por Val não são meramente sofrimentos individuais, eles são reflexos da sociedade em que a personagem está inserida e, portanto, socialmente constituídos. Ao menos é isso que se quer defender nesse trabalho. Para tal propósito, quer-se agora, antes mesmo de se apresentar a ideia de sofrimento social, descartar a ideia de que o sofrimento de Val seja sofrimento meramente individual. Para tal feitio, pretende-se agora descartar a ideia de que o sofrimento experienciado pela personagem de Regina Casé é fruto do desejo divino, assim como apenas consequência direta de seus atos.

\section{A visão providencialista do sofrimento}

Para se iniciar esta seção é importante salientar que se está partindo da leitura apresentada por Wilkinson e Kleinman (2016) acerca do providencialismo divino. Segundo os autores, por meio da perspectiva defendida por Richard Baxter (1615-1691), o sofrimento, visto por meio da perspectiva providencialista, é interpretado como uma questão de chamado e dever cristão, sobre a qual as pessoas deveriam aprender a "arte de sofrer" (art of suffering). Neste entendimento, todas as aflições são enviadas por Deus como punição pelo pecado ou como testes destinados a atrair crentes para um relacionamento mais próximo com o pecado (afastando os crentes do caminho de Deus, verificando quem realmente acredita no Poderoso).

Sob esta perspectiva, pensava-se que toda calamidade e infelicidade que acometia uma pessoa era um sinal de sua pecaminosidade ou um resultado direto dos pecados cometidos por pessoas de sua família ou comunidade. Outro aspecto dessa perspectiva era a ideia de que ao fazer uma pessoa sofrer Deus mostrava sua "afeição" pela pessoa. Por exemplo, com a morte de seu filho recém-nascido de difteria, Ralph Josselin (1616-1683) foi levado a pensar que se tratava de um castigo enviado por Deus por sua vaidade, assim como sua tendência a gastar muito tempo jogando xadrez. Voltando ao filme escrito e dirigido por Anna Muylaert, tem-se que, segundo a visão providencialista, o fato de Val ter que se afastar de sua filha Jéssica era a

\footnotetext{
${ }^{5}$ Neste caso, julga-se que durante o filme há aspectos suficientes para se defender a ideia de que Val sofre psicologicamente por ter tido que se afastar de sua filha. Que há o sentimento de não ter sido boa o suficiente para sua filha, i.e., de não ser uma boa mãe (autoculpabilização/autorresponsabilização).
} 
punição de Deus por Val ter pecado (ou porque alguém próximo a Val pecou; ou ainda porque Deus quer testar a fé da personagem de Regina Casé). Segundo essa visão, apenas caberá a Val aprender a arte de sofrer.

Segundo essa ideia de art of suffering, todos os eventos terrestres e as condições estabelecidas para os relacionamentos humanos são trazidos pela vontade de Deus e moldados por Sua Mão. Ainda nesta perspectiva, para aqueles que praticam a arte de sofrer, todas as dificuldades e adversidades devem ser pacientemente suportadas devido ao conhecimento de que Deus atua em todas as coisas. Haveria um propósito divino - este estaria por trás de eventos aparentemente aleatórios de sofrimento e, sob essa convicção, a Bíblia é consultada como um guia oficial para os tipos de ações que devem ocorrer como um meio de remediar a situação. Wilkinson e Kleinman (2016) afirmam que pesquisas de escritos e sermões cristãos, produzidos durante a Idade Média Europeia e o início do período moderno, revelam um notável consenso de opinião quanto ao significado do sofrimento humano, sobre o qual a Bíblia ensina que o sofrimento não é somente enviado por Deus como uma punição para o erro, mas também é usado por Ele como um meio de redimir Sua criação do pecado.

Já no Novo Testamento, os cristãos são aconselhados a tratar as dificuldades físicas e as perseguições como bênçãos de Deus e a se alegrar por Ele considerá-los dignos de participar dos sofrimentos de Cristo, devendo, é claro, tirar consolo do conhecimento de que, em última análise, sua recompensa estará no céu. Fazendo um paralelo com o filme Que Horas Ela Volta?, tem-se que Val não deveria sofrer, pelo contrário, deveria ficar feliz, pois seu infortúnio, sua infelicidade - por estar longe de Jéssica - era um sinal de que Deus estava olhando por ela e sua filha. Sendo que, se fosse o caso de Val não ver mais sua filha nesta vida, isso apenas significaria que este era o desejo de Deus e que no Reino Divino Val não estaria sob esse sofrimento. Ela havia sido escolhida por Deus e seus sofrimentos cessariam na terra.

Wilkinson e Kleinman (2016) afirmam que nesta ideia de que o sofrimento decorria do amor divino, alguns dos puritanos mais devotos também estavam inclinados a expressar ansiedade por não terem sofrido o suficiente, por exemplo, na medida em que a aflição serviu para santificar o crente, o clérigo e teólogo inglês John Downame (1571 - 1652) ele proclamou o sofrimento como um sinal da "afeição" de Deus. Da mesma forma, há registros do arcebispo da Igreja da Irlanda, James Ussher (1581-1656), preocupando-se com a possibilidade de que Deus não o amou mais porque ele não estava experimentando nenhuma dificuldade óbvia ou pressionando a questão da consciência. Assim, a elasticidade das doutrinas da providência era tal que, em teoria, um significado poderia ser encontrado para toda experiência de sofrimento 
- e, de fato, ser levado a sofrer foi considerado por muitos como uma parte necessária e até desejável de seu chamado cristão.

Segundo a ideia de Wilkinson e Kleinman (2016), é graças a essa elasticidade que a teoria providencialista sofreu um rápido processo de marginalização cultural, a partir da segunda metade do século XVII, de um modo geral, e deixou de ser considerada como tendo um papel legítimo nos principais aspectos intelectuais e políticos. Deste modo, nos círculos instruídos, tornou-se cada vez mais fora de moda explicar os eventos naturais como intervenções de Deus na história ou sinais portentosos de Seu julgamento iminente. Para os autores, em parte, a rejeição oficial do providencialismo é explicada como resultado das maneiras pelas quais ele foi exposto à força como fonte de desacordo intelectual absoluto e conflito social violento.

Neste ponto, é importante salientar que Wilkinson e Kleinman (2016) afirmam ser de grande valia entender que a marginalização cultural do providencialismo na vida intelectual e pública não levou à renúncia total da teoria providencialista do sofrimento humano, uma vez que ela continuou a ser uma maneira popular de explicar o sofrimento. Segundo os autores, nos duzentos anos seguintes, e particularmente depois de grandes desastres ou surtos de doenças epidêmicas, o providencialismo continuou a ser adotado por muitas pessoas como uma teoria explicativa do infortúnio, embora em sociedades que passaram por rápidas experiências de industrialização seja possível traçar um declínio acentuado em seu apelo cultural na segunda metade do século XIX.

Wilkinson e Kleinman (2016) admitem que ainda hoje é possível encontrar cristãos comprometidos que se arriscam a entender os eventos mundanos em termos do funcionamento da providência, no entanto, é geralmente aceito que, após os muitos eventos de violência em massa e atrocidades ocorridas no século XX, nunca entraria na mente da maioria das pessoas que Deus foi o responsável por esses acontecimentos, assim como a causa imediata do sofrimento de uma pessoa. Segundo muitos relatos, conforme as doutrinas cristãs tradicionais da providência divina se tornaram mais implausíveis e moralmente suspeitas, mais foi persuadida a visão de que nenhuma razão boa ou suficiente poderia ser encontrada para o sofrimento humano. Tornou-se cada vez mais difícil entender como experiências extremas de dor estavam relacionadas às intervenções de Deus na vida das pessoas.

Neste ponto, poder-se-ia questionar: todo o sofrimento experimentado por Val, todas as aflições, como não ter dinheiro para sustentar sua filha, ter que se submeter a jornadas exaustivas de trabalho, morar na casa de seus patrões, podem ser entendidas como um 
sofrimento que foi enviado por Deus como punição pelos pecados dessa mulher (ou de sua prole; ou ainda do seu ex-marido) ou como testes à fé de Val? Será que é uma boa explicação dizer que Deus quer que Val fique afastada de sua filha por mais ou menos 13 anos, pois assim elas estão participando do sofrimento de Cristo? Por mais que a personagem de Regina Casé fosse cristã, esse trabalho defende que o providencialismo divino e sua ideia de culpar Deus pelos sofrimentos socialmente evitáveis não constituem uma boa explicação para os infortúnios vivenciados pela empregada doméstica - ou de qualquer outra pessoa. A teoria providencialista do sofrimento divino acaba por encobrir os reais problemas. Assim, por mais que muitas pessoas possam acreditar que todos os sofrimentos mundanos sejam obras divinas, há bons indícios de que os sofrimentos, por exemplo, na vida de Val, podem ser explicados por meio da ideia de sofrimento social, i.e., que há aspectos culturais, históricos e sociais que explicam suas angústias e dores.

Para que estes pontos sejam explicitados, deve-se questionar os possíveis motivos pelos quais a empregada de Bárbara e José Carlos se encontra na situação descrita. Ao se fazer esse questionamento, vê-se, por exemplo, que esta mulher não teve grandes oportunidades de estudo, além de boas ofertas de trabalho em sua cidade natal. Deste modo, dada a pouca escolaridade, suas chances no mercado de trabalho foram drasticamente diminuídas, o que fez com que ela aceitasse um trabalho com pouca remuneração, o que a coloca em uma situação em que sua pessoalidade e sua própria família são deixadas de lado em nome do cumprimento do dever. Por que Val deixou sua cidade natal para ir morar em São Paulo? Um dos possíveis motivos é o fato da baixa oferta de empregos, assim como sua baixa escolaridade. As dificuldades sociais de se criar uma filha em Pernambuco nos anos 90 (agravando ainda mais as condições de baixa escolaridade e baixa oferta de empregos), além do imaginário - responsável por boa parte dos êxodos brasileiros - de que em cidades grandes como São Paulo e Rio de Janeiro as coisas são mais fáceis, são motivos complementares para se entender a trajetória de Val.

\section{A visão neoliberal do sofrimento humano: sofrimento individual e a ideia de que "você é responsável por seu sucesso ou fracasso"}

Se Val deixou sua filha e foi para São Paulo, o sofrimento não seria apenas consequência de suas ações? Será que Val se encontra na situação em que está devido às suas escolhas de vida? Será que ela não se esforçou o suficiente para sair dessa situação de sofrimento e dor? Para responder a essas questões, é necessário apresentar de modo mais detalhado os argumentos da posição neoliberal. A posição neoliberal (ou individualista) parte da ideia de negação do 
sofrimento enquanto um problema social e, deste modo, nessa perspectiva, tende-se a afirmar que os sofrimentos vivenciados pelas pessoas são sofrimentos individuais, que dizem respeito apenas a cada pessoa e que são consequência das ações e atitudes de cada um durante o curso de suas vidas. Segundo a ideia neoliberal, Val é a responsável direta, imediata e única de sua situação: a responsável por ter abandonado sua filha ainda criança, por não ter um bom grau de instrução escolar formal, a responsável por precisar ser babá e empregada doméstica etc.

Segundo a perspectiva neoliberal, as pessoas são as somas das suas decisões e, aparentemente, os fatores externos não influenciam as tomadas de decisões. A questão de, por exemplo, em Pernambuco nos anos 90 ter pouca oferta de trabalho e de Val ser filha de uma família de pessoas pobres e que não tinham dinheiro para mantê-la na escola, não são motivos para justificar a posição social de Val segundo a perspectiva neoliberal: Val abandou a filha porque quis - foi sua decisão. Ela poderia ter se esforçado e estudado mais. Ela poderia, segundo essa visão, ter conseguido um bom emprego em Pernambuco e não precisaria ter abandonado a filha quando criança. Como visto em Pinzani (2017, p. 363), a partir da "revolução neoliberal" dos anos 1980 e principalmente 1990, portanto, há uma ideia de responsabilização (ou culpabilização) dos pobres por suas situações.

É importante salientar que julga-se que essa visão neoliberal do sofrimento - que nega o sofrimento social, e acredita que apenas há sofrimentos individuais causados pelas próprias ações dos indivíduos - está intimamente imbricada com a ideia apresentada por Wilkinson e Kleinman (2016) de que houve um abandono do sentimentalismo (perspectiva sobre a qual as pessoas se preocupavam umas com as outras) das teorias éticas e políticas em nome de uma individualização (e individuação) das pessoas, implicando que, agora, cada pessoa seria a responsável por sua própria vida. Segundo a perspectiva neoliberal, portanto, apenas o desejo por sucesso (e tentativa de evitar o fracasso - o sofrimento) era o que movia as ações humanas. Destaca-se que nesse trabalho adota-se a perspectiva de Renault (2010) sobre o neoliberalismo. Segundo essa visão, o neoliberalismo (entendido como sistema social) caracteriza-se, entre outras coisas, tanto pela emergência de novas condições de trabalho ${ }^{6}$, quanto por sua tendência natural à exclusão social. Para Renault (2010), pode-se afirmar que esses fatos geram dois problemas de sofrimento social: as novas condições de trabalho degradante levam a novas dificuldades subjetivas - que o autor chama de sofrimento do trabalho; e a exclusão social se

${ }^{6}$ Poder-se-ia aqui usar como exemplo o precariado, i.e., a grosso modo, aqueles trabalhadores que têm seus contratos de trabalho como pessoas jurídicas, para que assim não recebam os benefícios previsto por lei, como férias, seguro-desemprego etc., que recebem apenas as horas de trabalho na empresa e não possuam vínculo empregatício de fato, apenas contratos de períodos curtos em determinados projetos. 
entrelaça, mais uma vez, com as questões de dimensões sociais e psicológicas, tendo como consequência uma situação social ainda pior.

Deste modo, segundo o pensamento de Renault (2010), o sofrimento social devido à exclusão é um obstáculo à crítica (e à transformação), pois faz com que as pessoas que estão padecendo deste mal se sintam culpadas pela situação em que se encontram (autorresponsabilização) e faz com que muitas vezes apresentem casos de desemprego crônico, sentimentos de vergonha e depressão. O autor nota que isso é cada vez mais comum, contudo não vê esses problemas como resultados apenas de ações individuais. Para Renault (2010), a leitura neoliberal do sofrimento do trabalho, assumindo o entrelaçamento de problemas sociais e psicológicos como problemas meramente individuais, faz com que se escondam os reais motivos do sofrimento, para, então, responsabilizar os próprios indivíduos. Sendo que esse quadro não é compatível com a crítica social e a ação política, na visão do autor.

Em Que Horas Ela Volta? vê-se claramente esse processo de culpabilização, pois Val se culpa por ter deixado a filha, ainda criança, em Pernambuco para tentar uma vida melhor em São Paulo. Este fato fica claro quando Val descobre que Jéssica teve um filho e o deixou em Pernambuco para prestar o vestibular em São Paulo. O sentimento de culpa, a autoculpabilização (ou autorresponsabilização), está intimamente ligado à ideia de que cada pessoa é a responsável direta por sua vida, sem levar em conta os motivos - i.e., as condições sociais - que a fizeram agir de determinada maneira. No caso em voga, a autoculpabilização é entendida como uma ação meramente individual da retirante pernambucana. A partir da autorresponsabilização fatos como o de não haver emprego na cidade natal ou desejo - que é criado socialmente - de ascendência social não são vistos como determinantes nas escolhas de vida de Val.Neste ponto, cabe salientar a ideia de Frost e Hoggett (2008) de que os relatos sociológicos do estigma e da vergonha chamam a atenção para as relações sociais que reproduzem as lesões psíquicas, sobre as quais não se permite compreender como o sujeito é constituído por essas experiências, sobre o que torna necessária uma abordagem psicossocial focada na relação entre as biografias individuais e os processos sociais e, portanto, que se preocupe com os mecanismos pelos quais as relações sociais são internalizadas. Por trás desta ideia, os autores defendem que dentro do "liberalismo iluminista" há a visão particular de um sujeito humano racional e autônomo, do qual tanto a política (policy) social tradicional quanto as alternativas progressistas se baseiam, mas que deveria ser eliminada, em favor da alternativa da vida emocional (emotional life) no centro da política social e da prática do bem-estar, mantendo uma perspectiva crítica sobre a questões de poder. 
Frost e Hoggett (2008) afirmam que, segundo a visão neoliberal de sujeitos livres e autônomos, a sensação de inadequação é internalizada no próprio sistema de significado do indivíduo; a vergonha é vivenciada de maneira privada, pessoal, e assim é abarcada pelo sujeito. Deste modo, o indivíduo vive a sensação de que não se enquadra mais no grupo e a vergonha, então, equivale a sérios danos identitários, com ramificações para vários aspectos da individualidade. Segundo os autores, a individualização como experiência de dor (hurt) e perda (loss) pode deixar os indivíduos se sentindo muito sozinhos ${ }^{7}$ e “[...] a vergonha, em particular, pode levar a um afastamento da intimidade, das redes, das ligações. Isto pode limitar ainda mais a capacidade do sujeito de se mover propositadamente e com confiança no mundo [...]" (FROST; HOGGETT, 2008, p. 448).

Não se deterá aqui nas questões concernentes aos sujeitos pós-liberais, defendidas pelos autores, nem se voltará às questões do sentimentalismo (nas palavras de Wilkinson e Kleinman). Interessa neste trabalho a consideração feita por Frost e Hoggettt (2008) de que em sociedades como a Grã-Bretanha e os Estados Unidos - lugares onde se argumenta que a globalização requer flexibilização - as consequências da crença neoliberal de que "não existe sociedade" estão sendo experimentadas ${ }^{8}$. Sendo que nesses países (mas não só, o caso do Brasil Pós-Golpe de 2016 e sob a presidência de Bolsonaro é paradigmático quanto a isso) parece que os sindicatos se tornaram impotentes e as comunidades tradicionais se fragmentaram, as desigualdades sociais aumentam à medida que os super-ricos prosperam na ausência de intervenção do governo. Dentro do capitalismo pós-industrial, pós-coletivo e consumista, a compreensão da distância entre a experiência real e a ilusão popular de que não há classe, de que com determinação suficiente alguém pode ser qualquer coisa, é dolorosa de suportar, pois a realidade das classes e as limitações cruéis da pobreza, por exemplo no nível educacional, na entrada na universidade, nas oportunidades de emprego e em uma vida respeitada e confortável, são assim mascaradas.

${ }^{7}$ Para Wilkinson e Kleinman (2016) o tecido social do mundo está dilacerado, e pode muito bem ser deixado para além do reparo. Suporta-se o insuportável. Essa experiência de perda de um mundo moral é uma espécie de privação social ligada tanto aos desastres naturais como aos provocados pelo homem e registrada no corpo individual e coletivo com uma tristeza, desorientação, anomia e anseios insustentáveis.

${ }^{8}$ Defender a ideia de que "não existe sociedade", aqui, significa que não há cooperação social. É afirmar que não há um sistema social e político; que não há história. Há apenas, segundo essa ideia, indivíduos: mônadas isoladas; pessoas são como cogumelos - que brotam na terra. Aqui, dizer que "não existe sociedade" é dizer que as posições sociais não são determinadas pelo nascimento; que não existe racismo, xenofobia e nem preconceito de gênero; é dizer que a filha de uma empregada doméstica tem as mesmas chances que o filho dos patrões; e que qualquer política governamental - como as cotas sociorraciais - são "injustas" (sic), são um privilégio para as pessoas negras e pobres. 
Deste modo, para Frost e Hoggett (2008), sujeitos (subjects) do sofrimento social podem não atrair facilmente a compaixão se não se apresentarem como vítimas inocentes, mas como pessoas agressivas, ressentidas ou suspeitas, cuja mágoa e perda são dirigidas a outros e não a si próprios. Recorda-se aqui o diálogo entre Fabinho e Val, onde o filho dos patrões da personagem de Regina Casé afirma que Jéssica era muito segura de si, muito autoconfiante. Esse diálogo exemplifica o ponto que os autores querem mostrar: Jéssica, por não se sentir culpada por sua situação (e nem culpar sua mãe), ao invés de ser vista como uma pessoa que sofre socialmente, que carrega em suas costas um fardo social pesado demais (mulher jovem, nordestina, filha de empregada doméstica, mãe durante a adolescência etc.), é vista pelo filho de Bárbara e José Carlos como autoconfiante demais - sendo que há um claro juízo de valor negativo na afirmação de Fabinho. Deste modo, para Frost e Hoggett (2008), o sofrimento é duplo: a pessoa se torna "antipatizada" (disliked) e indesejada em grupos sociais, lutando para formar amizades ou para encontrar amor pessoal e estima, e desta maneira o dano (hurt) produz mais mágoa: rejeição e demissão, mais perdas e mais sofrimento. Relações íntimas e vínculos sociais mais amplos podem se tornar difíceis de sustentar, e a pessoa envolvida nisso pode tornar-se atomizada, anômica (anomic) e solitária. Sendo que a anomia reduz as possibilidades de reconhecimento mútuo e de garantia de identidade.

Tendo em vista as ideias apresentadas por Renault (2010) e Frost e Hoggett (2008), julgamos que é possível ler a ideia de Wilkinson (2005) como complementar. Wilkinson (2005), com base nos escritos de Hannah Arendt, defende que a perspectiva neoliberal do sofrimento (que nega o sofrimento enquanto fenômeno social) é aquela em que as condições sociais são tais que as pessoas começam a se tratar (e se sentirem) como descartáveis (superfluous) ${ }^{9}$. Isto é, pode-se dizer que, em seus estudos, Arendt percebeu que há uma desumanização das pessoas (ou em termos marxistas, uma coisificação das pessoas). Segundo Wilkinson (2005), Arendt identifica o caráter descartável das pessoas sempre que elas começam a ser reduzidas a um estado de "sem-teto", "sem estado", "fora da lei", "não-ocupado", "sobrecarregado socialmente" e "desempregado". "[...] Nesta análise, o processo social que torna possível o extermínio de pessoas como não mais do que 'material humano descartável', enraíza-se onde quer que os indivíduos sejam privados dos seus direitos básicos à vida, à liberdade e à busca da felicidade. [...]" (WILKINSON, 2005, 92).

\footnotetext{
${ }^{9}$ Se utilizará como tradução para o termo em inglês superfluous a palavra em português descartável - e não supérfluo, que seria a tradução literal, pois julgamos que a ideia de "descartabilidade" tem mais a ver com a mensagem a qual se quer passar do que com a ideia de supérfluo, principalmente sob a perspectiva neoliberal do sofrimento.
} 
Wilkinson (2005) afirma que, de maneira similar, na literatura sobre o sofrimento social há numerosos estudos que enfatizam que quando as pessoas se tornam vítimas de atos extremos de violência elas não são mais vistas como "humanos" por seus torturadores e carrascos. Isto é, quando são desumanizadas, são vistas como coisas, como descartáveis. Assim, para o autor, uma vez que os estudos sobre o sofrimento social procuram expor a natureza insidiosa desses processos de "desumanização", acabam por voltar suas atenções às maneiras pelas quais as violações da dignidade humana das pessoas se originam em comportamentos sociais e práticas culturais que adquirem o status de aspecto "normal" no modo com que os indivíduos interpretam e respondem à sua realidade ${ }^{10}$. Por exemplo, uma mulher abandonar sua filha em sua cidade natal para tentar uma vida melhor para si e sua família em uma grande cidade, em outro estado, torna-se uma ação normal: não é visto com espanto, não é visto como um exemplo claro de que a organização social - ao qual ela está inserida - tem algum problema e que precisa ser corrigida por meio de ações políticas o quanto antes. Segundo Wilkinson (2005), essa violência diária é melhor percebida pelas pessoas pobres que vivem em sociedades em desenvolvimento - pelas pessoas que lutam pela existência em condições de extrema pobreza. $\mathrm{O}$ autor reconhece que

[...] o sofrimento ocorre de forma que pode não ser imediatamente aparente para os observadores "externos"; pois eles descobrem que isso não é tanto em relação ao trauma da experiência física imediata da pobreza, mas mais em termos de como tais eventos subsequentemente deixam suas marcas sobre os significados de si e da sociedade (WILKINSON, 2005, p. 93).

Para Wilkinson (2005), na literatura do sofrimento social a experiência pessoal do sofrimento é simbolicamente representada nos domínios da vida pública. Pessoas que sofrem relatam que, por meio da linguagem cotidiana e das práticas sociais, elas são forçadas a viver no rescaldo (aftermath) de eventos dolorosos que tornam os fatos de suas aflições ainda piores, mais violadores. Neste ponto, é salutar se ter em mente outro trabalho de Wilkinson, junto com Kleinman. Neste trabalho, Wilkinson e Kleinman (2016) afirmam que, como frequentemente é sugerido, sob as condições da modernidade - com a intensificação da experiência individual a experiência social de sofrimento adquiriu um tom e força distintos. Em parte, isso parece estar relacionado à peculiaridade das maneiras pelas quais as pessoas estão agora socialmente dispostas a sentir, interpretar e responder às tribulações de si e dos outros. E, ao mesmo tempo, muitos compreendem-se como testemunhas do desenvolvimento de estruturas sociais e

\footnotetext{
${ }^{10}$ Apenas a título informativo, para Wilkinson (2005) os estudos sobre o sofrimento social vão muito além dos estudos de Arendt sobre a banalidade do mal, pois cabe aos estudiosos detalhar as formas particulares pelas quais a "violência" é feita à humanidade no contexto social da vida cotidiana.
} 
circunstâncias materiais que estão destinadas a aumentar a incidência e a escala da miséria humana.

Segundo Wilkinson e Kleinman (2016), somente na modernidade os sistemas sociais e os processos industriais foram projetados para propósitos de administração do genocídio, e testemunha-se o desenvolvimento de práticas institucionais que permitem que os indivíduos funcionem com indiferença burocrática e se desassociem moralmente dos comportamentos organizacionais que dão poder aos regimes totalitários para perpetuar tal horror. Os autores afirmam que, por muitos anos, os analistas sociais notaram que as sociedades modernas são compostas por arranjos institucionais que posicionam os indivíduos a uma distância moral do sofrimento dos outros. Uma grande parte da vida é conduzida de acordo com convenções sociais e meios de troca que obrigam as pessoas a lidarem com as outras em termos puramente abstratos e instrumentais, e, nesse sentido, argumenta-se que esta situação ética é bem diferente de qualquer outro período da história.

Desta maneira, através da adoção de atitudes de senso comum e comportamentos rotineiros, as pessoas são colocadas em posições imprudentes de processos sociais e transações econômicas que trazem grandes sofrimentos a estranhos distantes. De fato, por essa razão, o problema do sofrimento mudou não apenas em relação à escala e à força destrutiva das catástrofes que desintegram as sociedades, mas também de acordo com o grau em que elas são realizadas como resultado não intencional de práticas sociais que em seu ponto de origem pode bem ser visto como comum e benigno. A modernidade deu origem a condições sociais em que a manutenção do "estilo de vida" e a busca da "aspiração do consumidor" em um extremo do globo estão estruturalmente implicadas na intensificação das forças de destruição, violência e opressão do outro. Habita-se uma sociedade global sobre a qual as práticas da vida cotidiana estão ligadas em algum momento na perpetuação de arranjos sociais e culturais que causam grande dano a populações remotas. Assim, parece fácil demais que as pessoas se relacionem por meio de uma atitude de indiferença moral com o sofrimento de um grande número de pessoas, donde se pode chegar a ver o sofrimento como um fato "banal" da vida.

Ao mesmo tempo, na modernidade, é possível apontar para muitas arenas sociais e contextos culturais sobre os quais a experiência do sofrimento humano atrai uma quantidade sem precedentes de atenção moral e interesse público. Deste modo, segundo Wilkinson e Kleinman (2016), um dos aspectos mais desconcertantes da vida social moderna reside no fato de que enquanto se gasta muito tempo em arranjos institucionais que se dispõem a pensar e agir sem sentir pelos outros, também se é levado a ambientes sociais sobre os quais se é conduzido 
para ser emocionalmente preocupado com o bem-estar dos estranhos. É muito provável que as contradições morais e políticas que surgem para as pessoas em conexão com a experiência de estarem posicionadas como testemunhas remotas do sofrimento de outras pessoas não tenham precedentes. A disseminação em massa das imagens de sofrimento através de formas comerciais de reprodução e troca cultural está provocando uma grande transformação na experiência da subjetividade social, particularmente na medida em que isso "normaliza" uma consciência vívida dos outros que estão sofrendo em contextos que excluem possibilidades de participação no debate público e lhes é negada a opção de um compromisso compassivo com as necessidades humanas. Os autores afirmam que, nos tempos modernos, o problema do sofrimento adquiriu uma capacidade sem precedentes de confundir as sensibilidades morais (moral sensibilities) e poderes da razão (powers of reason).

Deste modo, julga-se que a interpretação neoliberal do sofrimento, tão comum e aceita, ao afirmar que Val é a única responsável por sua condição social, falha miseravelmente em explicitar os problemas que estão por trás daquelas condições as quais a mulher está submetida. A perspectiva neoliberal (ou individualista) do sofrimento encobre e cria um "mar" de ilusões quando culpabiliza a própria pessoa pela sua condição social; sendo que autoculpabilização pode se tornar um fardo pesado demais para algumas pessoas, gerando assim outros problemas: desemprego crônico, depressão, ansiedade etc., que em um primeiro olhar são apenas sofrimentos individuais, mas que analisados sobre a lupa das condições sociais são percebidos também como casos de problema social. Deste modo, julga-se correto afirmar que assim como a visão providencialista não dava conta de explicar o sofrimento de Val (e as demais histórias de sofrimento social escondidas sob a tutela do desejo de Deus), a visão neoliberal também não consegue tal explicação. No entanto, o mais preocupante é que, hoje, infelizmente, é a visão mais aceita na sociedade.

A autoculpabilização pressuposta pela visão neoliberal do sofrimento é, portanto, a maneira de um setor da sociedade (os detentores do poder político e financeiro) fazer com que os reais problemas de distribuição e redistribuição de renda e riqueza, assim como de poder, das relações de gênero etc., não sejam percebidos, pois com a individualização das pessoas, com a ideia de que cada um é o responsável direto pelo seu sucesso ou seu fracasso, com a visão de que o sofrimento é meramente individual e não possui caráter algum que seja socialmente compartilhado, são encobertos por uma cortina de fumaça. Dentro dessa visão de autoculpabilização expressa pelo neoliberalismo, tem-se que um sistema que permite desigualdades exorbitantes não é colocado em xeque e a necessidade de políticas públicas, 
como o caso do Bolsa Família ou as cotas sociorraciais, é vista como assistencialista (dá-se o peixe, mas não se ensina a pescar), em um contexto sobre o qual as pessoas pobres são vistas como as próprias culpadas pelas suas situações e "[...] de preferirem sobreviver à custa dos outros em vez de viver de seus esforços [...]" (PINZANI, 2017, p. 354). Portanto, não cabe ao Estado fazer qualquer coisa, deve-se deixar que o mercado se autorregule, seja lá o que isso possa significar na vida de pessoas como Val e Jéssica. Esquece-se, porém, que nem todas as pessoas moram próximas a rios ou mares ou possuem o material necessário (como tarrafas e varas) para poderem pescar.

\section{Sofrimento Social}

Para se defender o conceito de sofrimento social, primeiro se descartou o providencialismo divino e, posteriormente, tentou-se desacreditar a lógica neoliberal de autoculpabilização das pessoas pobres e constantemente marginalizadas. Nesta seção tem-se por objetivo apresentar a ideia de sofrimento social, e explicitar, finalmente, por que o caso de Val seria um caso de sofrimento social. Começa-se pela afirmação de Wilkinson e Kleinman (2016) de que, ao longo da história e em todas as culturas, o sofrimento humano foi identificado como uma "condição limite" através da qual se pode aprender algumas das verdades mais básicas sobre o estado de ser e de estar no mundo.

A esse respeito, parece que a vulnerabilidade da condição humana é tal que se está sempre fadado a tomar a impossibilidade de se retirar do sofrimento como um guia amargo para o ego e a sabedoria social. No registro do sofrimento humano, repetidamente depara-se com o extremo paradoxo de que, através de experiências que acarretam o mais terrível desenraizamento da vida, se é levado à compulsão de buscar o que realmente importa na vida. Isso faz dela uma experiência intensamente moral. Deste modo, segundo os autores, o sofrimento social é um conceito desenvolvido para entender como o sofrimento das pessoas é causado e condicionado pela sociedade. Ele é projetado para documentar formas de experiência social e condições vividas que determinam como o sofrimento acontece e o que isso causa às pessoas. No estudo do sofrimento social, as dores e as misérias das pessoas são tomadas como base para tornar nosso estado social uma questão de investigação crítica e moral.

Em um mundo em que o avanço tecnológico é tal que conseguiria suprir as necessidades básicas - de alimentação, saneamento etc., - de todas as pessoas, isso não se efetiva, pois frente à ideia de suprir as necessidades básicas está a necessidade (ou a ideia) do lucro. Isso faz com 
que Bernstein (2005), com base em Adorno, afirme que o sofrimento social é o sofrimento de uma pessoa (ou grupo de pessoas) que poderia ser evitado se o mundo fosse organizado de outro modo, i.e., é um sofrimento socialmente evitável. Para Frost e Hoggett (2008) a ideia de sofrimento denota os componentes entrelaçados de pensar, sentir, responder e agir, e este é visto como um fenômeno duplo: reflexivo e não-reflexivo; i.e., às vezes pode ser pensado criticamente e criativamente (originalmente), e às vezes é encarnado, encenado ou projetado precisamente porque não pode ser pensado. Segundo Frost e Hoggett (2008) deve-se estudar as relações entre as compreensões psicossociais da subjetividade - o eu não-unitário (the nonunitary self) - com as implicações para a agencia humana (human agency), de modo a considerar como modelos de sofrimento psicossocial fornecem uma estrutura para entender a experiência dos sujeitos e como sua agência é expressa.

Frost e Hoggett (2008) afirmam que tanto o mundo interior de sofrimento psíquico e o mundo exterior de opressão social estrutural são constitutivos de das compreensões subjetivas e da capacidade de agência humana (e as suas possibilidades). Segundo os autores, o sofrimento cultural é em si o "Outro" para a modernidade. O sofrimento dá expressão à voz passiva em vez da ativa, ao eu como objeto e ao que é frequentemente crônico e duradouro, e não ao que está aberto à engenharia social e às soluções rápidas. Assim, por razões políticas e culturais, as democracias ocidentais estão, em parte, em fuga do sofrimento, e aqueles que são os sujeitos do sofrimento tornam-se o "Outro" de uma modernidade orientada para a conquista.

Segundo Wilkinson e Kleinman (2016), analisar o significado social e os limites do sofrimento humano requer que se reconheça desde o início que se está lidando com uma experiência profundamente moral. O sofrimento ocorre como um ataque intensamente violento e prejudicial à pessoalidade humana. É uma experiência esmagadora e, muitas vezes, extremamente negativa. A dor do sofrimento sinaliza que algo muito ruim está acontecendo e que há algo terrivelmente errado com o mundo e a maneira como este é socialmente organizado. Como tal, não apenas emite uma demanda por escrutínio crítico, mas também por ações de melhoria para se opor aos danos que isso causa às pessoas. Muita coisa está em jogo para as pessoas. Dentro do quadro analítico do sofrimento social, a tarefa da compreensão social exige que os cientistas sociais trabalhem de modo que estejam particularmente atentos aos dilemas da experiência moral e às grandes tensões que as pessoas enfrentam na luta para levar uma vida moral, incluindo o uso da compreensão.

Com estas ideias em mente, julga-se que é possível afirmar que o caso de Val trata-se de um caso de sofrimento social, pois a personagem de Regina Casé nasceu e viveu em uma 
sociedade extremamente marcada pelas desigualdades sociais de cor e de gênero, sobre a qual desde o início suas expectativas de vida (e os planos de um bem viver) já estavam prédeterminadas, ainda que não formalmente, uma vez que o Brasil não é uma sociedade de castas, mas substancialmente, já que Val deu o "azar" de nascer em uma família pobre em uma sociedade extremamente desigual. Deste modo, tentou-se neste trabalho apresentar e defender que os motivos pelos quais Val não teve oportunidades de estudo, por ter deixado sua filha em sua cidade natal enquanto foi para São Paulo tentar uma vida melhor, o fato dela ter conseguido apenas trabalhos de menor remuneração etc., são expressões da organização social. E, como consequência, todas as dores e sofrimentos advindos dessas "escolhas" de Val são na verdade consequências sociais da organização social e, portanto, são sofrimentos que poderiam ser socialmente evitáveis, mas que são mantidos pelo modo como a sociedade é organizada.

\section{REFERÊNCIAS BIBLIOGRÁFICAS}

BERNSTEIN, J. M. Suffering Injustice: Misrecognition as moral injury in critical theory. In: International Journal of philosophical Studies, 13/3, 303-324. 2005.

FROST, Liz; HOGGETT, Paul. Human Agency and Social Suffering. In: Critical Social Policy, 28/4, pp. 438-460.2008.

PINZANI, Alessandro. "Vai trabalhar, vagabundo": retórica antipobre e aspectos normativos de uma teoria da pobreza. In: SILVA, H. A. (Org.). Sob os olhos da crítica. Reflexões sobre democracia, capitalismo e movimentos sociais. 1ed.Macapá: UNIFAP, 2017, p. 348-388.

QUE HORAS ELA VOLTA? Direção e Roteiro: Anna Muylaert.Interpretes: Regina Casé; Camila Márdila; Michel Joelsas; Karine Teles; Lourenço Mutarelli. Produção: Fabiano Gullane; Caio Gullane; Débora Ivanov; Anna Muylaert. Coprodução: África Filmes; Globo Filmes. 2015.

RENAULT, Emmanuel. A Critical Theory of Social Suffering. In: Critical Horizons, 12-2, 221-241.2010.

WILKINSON, Iain. Suffering. A Sociological Introduction. Cambridge: Polity, 2005.

WILKINSON, Iain; KLEINMAN, Arthur. A Passion for Society. How We Think about Social Suffering. Berkeley:University of Califórnia Press, 2016. 